\title{
A dimensão comunicacional da inovação
}

The communicational dimension of innovation

La dimensión comunicacional de la innovación 


\section{Resumo}

Estudo sobre a dimensão comunicacional de inovação a partir das perspectivas do impacto das tecnologias de informação e comunicação (TIC's) na pesquisa e desenvolvimento. 0 estudo concluiu que a quantidade de informação disponível atualmente possibilitou mais opções de pesquisas e desenvolvimento para os empreendedores, porém há necessidade, dentro desse cenário de avanços tecnológicos, de reflexão crítica sobre o impacto dessas tecnologias no mercado de trabalho, na formação educacional, na privacidade dos dados e na livre circulação de ideias.

\section{PALAVRAS-CHAVE: INOVAÇÃO • ECOSSISTEMA DE INOVAÇÃO • COMUNICAÇÃO.}

\section{Abstract}

Study on the communicational dimension of innovation from the perspectives of the impact of information and communication technologies (ICT) on the research and development. The study concluded that the amount of information currently available allowed more research and development options for entrepreneurs, but there is a need, within this scenario of technological advances, for critical reflection on the impact of these technologies on the labor market, on educational formation, data privacy and the free circulation of ideas.

\section{KEYWORDS: INNOVATION・INNOVATION ECOSYSTEM・COMMUNICATION}

\section{Resumen}

Estudio sobre la dimensión comunicacional de la innovación desde la perspectiva del impacto de las Tecnologías de la Información y la Comunicación (TIC) en la investigación y el desarrollo. El estudio concluyó que la cantidad de información disponible en la actualidad permite a los empresarios más opciones de investigación y desarrollo, sin embargo, es necesario, dentro de este escenario de avances tecnológicos, una reflexión crítica sobre el impacto de estas tecnologías en el mercado laboral, en la formación educativa, en la privacidad de datos y en la libre circulación de ideas. 


\section{INTRODUÇÃO}

$\mathrm{V}$

ive-se um novo momento, em que as mudanças econômicas, sociais, políticas e educacionais, assim como as tecnologias, impactaram de maneira significativa a nossa percepção do mundo.

A inovação aberta, por exemplo, que seria inimaginável há cinquenta anos, hoje é praticada por muitas empresas, apresentando uma nova dinâmica de relação entre pares. Ao analisar a questão educacional, é possível encontrar a Open University, no Reino Unido, como a primeira instituição a oferecer ensino totalmente a distância (Cieb, 2016, p.13). Também há os recursos educacionais abertos (REA) no estímulo do uso e reuso de conteúdos compartilhados na rede. Esses modelos foram impulsionados pelas TIC's, que possibilitaram a troca de conhecimento, diminuindo o custo da inovação. 0 pano de fundo de todos os modelos abertos é o compartilhamento da informação. Outro ponto relacionado com as TIC's foi o barateamento tecnológico de ferramentas de produção de compartilhamento de conteúdo. Isso oferece ao empreendedor um ecossistema de inovação em que ele pode pesquisar, desenvolver, divulgar e vender suas ideias. A quantidade e a qualidade da informação disponível na rede possibilitam ao empreendedor encontrar parceiros, financiamento, desenvolvedores e espaço para testar as ideias sem o alto custo ou estrutura, como acontecia em épocas em que a inovação fechada era praticamente a única possibilidade de pesquisa e desenvolvimento (P\&D).

\section{O ECOSSISTEMA DA INOVAÇÃO NA PERSPECTIVA EDUCACIONAL}

O Fórum Econômico Mundial apresentou - em 2016 - um relatório mostrando que 35\% da população mundial não realiza nenhum tipo de atualização profissional. De acordo com o documento, isso cria lacunas específicas em cada país e impacta as perspectivas de futuras economias.

Um dos pontos levantados no relatório é a falta de conexão entre os sistemas educacionais e as habilidades necessárias para atuar no mercado de trabalho atual. Apesar de haver sistemas que já procuram desenvolver habilidades cognitivas, as não cognitivas - relacionadas com a capacidade de um indivíduo para colaborar, inovar, autodirecionar-se e resolver problemas - são cada vez mais importantes.

Alguns sistemas de educação atuais também são estruturados de uma maneira não adequada para os mercados de trabalho atual ou futuro. Em muitos países, os investimentos em educação não resultaram em retorno do mercado de trabalho para os indivíduos e suas famílias, devido ao desemprego, ao subemprego ou a grandes segmentos demográficos que ficaram economicamente inativos. Em outros, independentemente dos níveis de educação, o trabalho pode ser precário, insuficientemente para explorar o conhecimento existente, ou a pessoa pode não investir na aprendizagem e na reconversão que deve ocorrer ao longo do ciclo de vida do trabalho.

A mudança tecnológica pode agravar ainda mais o mercado de trabalho, mas, por outro lado, fornece novas oportunidades para que as instituições de ensino transformem essas preocupações tanto em aprendizagem como em emprego. Essas oportunidades precisam ter relação como o desenvolvimento regional e o bem-estar de todos.

Governos, líderes empresariais, instituições educacionais e indivíduos devem entender a magnitude da mudança em andamento e repensar fundamentalmente a cadeia de valor do talento global. Para ser proativo em nossa resposta às necessidades futuras de economias, sociedades e indivíduos, devemos repensar o que significa aprender, o que significa trabalhar e qual o papel das várias partes interessadas para garantir que as pessoas possam cumprir o seu potencial. 
ANO 16 • NÚMERO $31 \cdot 2$ º SEM. 2019 • ORGANICOM

0 potencial de tecnologia para transformar o acesso e a qualidade educacional tem sido bem documentado. Além disso, num mundo em que $13 \%$ da população em idade ativa são trabalhadores por conta própria, 4\% estão desempregados, $7 \%$ estão subempregados e 20\% são inativos (além de três em cada quatro pessoas com mais de 65 anos de idade cada vez mais saudáveis e, em muitos casos, altamente qualificadas) - no total, cerca de $44 \%$ da mundial população em idade laboral ou 2 bilhões de pessoas - novas tecnologias também podem apresentar enorme oportunidade para desbloquear e nutrir 0 potencial de capital humano de uma parcela considerável da população em todo o mundo.

Esse potencial de capital humano não está relacionado somente às questões técnicas sobre o uso ou conhecimento das tecnologias. De maneira geral, envolvem-se docentes, discentes e áreas administrativas de uma instituição de ensino para o desenvolvimento de competências e reflexões sobre a aplicação e utilização da tecnologia dentro das instituições.

\footnotetext{
As habilidades requeridas nessa perspectiva vão além do simples conhecimento técnico, capacidade de uso das tecnologias e consumo de informação. Envolvem o letramento digital, o desenvolvimento de competências, como o pensamento crítico e criativo, resolução de problemas, Design Thinking, trabalho em equipe, gestão de projetos, a capacidade de criar, reutilizar e revisar conteúdos digitais para adequar a uma clientela ou necessidade específica. Integrar as Tecnologias da Informação e Comunicação (TIC) ao currículo de forma qualitativa para aproximar a escola da cultura digital é um desafio global. Desafio que passa, em primeira instância, pela formação inicial e continuada de docentes e, não menos importante, pela incorporação de tendências que já fazem parte do cotidiano da sociedade conectada, como personalização, práticas colaborativas em redes digitais, gamificação, metodologias ativas de aprendizagem, uso de celulares e outros dispositivos móveis e adoção de softwares livres e conteúdo aberto. (Cieb, 2016, p.10, grifos do autor)
}

Essas vertentes possibilitam aos atores do sistema educacional - professores, alunos, gestores pedagógicos, gestores públicos e desenvolvedores de soluções e produtos tecnológicos - se engajar em projetos mais interessantes e alinhados com o contexto atual da sociedade do conhecimento, buscando gerar impacto positivo ao considerar um cenário que estimule a solução de problemas complexos, a comunicação, a avaliação crítica, e, por fim, a inovação.

\section{A DIMENSÃO COMUNICACIONAL DA INOVAÇÃO}

A cada nova invenção tecnológica de sucesso o homem volta a olhar com mais atenção a questão da organização do espaço e do tempo. Ao fazer uma leitura recente da história da humanidade, é possível perceber o impacto dos meios técnicos de comunicação e como eles alteraram a dimensão de espaço e tempo da vida social, uma vez que "todos os meios técnicos têm uma relação com os aspectos de espaço e de tempo da vida social, mas o desenvolvimento da tecnologia da telecomunicação na segunda metade do século XIX foi particularmente significativo a este respeito" (Thompson, 2008, p.36).

A organização do tempo na sociedade primitiva estava ligada à conformação social e às formas de religião, como observado por Durkein na obra Primitive classification (1903), "a divisão entre dias, meses, anos, etc. corresponde à periódica ocorrência dos fatos dos ritos, das festas e/ou cerimônias públicas" (Sichel, 1989). Percebemos que as transformações na vida social em função de novas tecnologias de comunicação e transporte se modificam já no século XIX, fazendo com que cada cidade, vila ou aldeia tivesse o mesmo padrão de tempo. Com a construção das ferrovias, houve uma constante pressão para calcular o tempo em níveis supralocais, originando o tempo universal padronizado. A influência de novas tecnologias nos hábitos sociais é constante, assim, conforme vão surgindo novas tecnologias, a experiência com relação ao tempo e espaço também vai se transformando.

Não só a questão do tempo e espaço tem se modificado, as tecnologias digitais deram origem a uma nova combinação de big data e práticas computacionais que permite a coleta latente de dados em massa, a modelagem computacional sofisticada e 0 aumento da capacidade das pessoas com recursos e acesso a essas ferramentas para realizar pesquisas altamente eficazes 
e de engenharia social em esferas políticas, civis e comerciais (TÜFEKÇI, 2014). Tudo isso em função das tecnologias e das informações digitais que cada vez mais são compartilhadas na internet.

A popularização do acesso à internet - somada aos aparelhos móveis com acesso à rede, ferramentas de comunicação on-line e serviço de computação em nuvem, big data e análise de dados estruturados - trouxe uma nova relação ao ambiente social e de trabalho. É possível identificar a ação e cooperação em diversas áreas de conhecimento. Na educação, por exemplo, é importante pontuar a mudança nas relações entre instituições de ensino, professor e aluno.

Estudos relacionam as novas tecnologias de comunicação e informação e os impactos que ocorreram nos últimos anos na educação, porém alguns (Sodré, 2009; Prensky, 2010) afirmam que a tecnologia em si não altera as relações pedagógicas.

A tecnologia pode tanto reforçar uma visão individualista e totalitária como oferecer ao aluno a possibilidade de pesquisar sobre qualquer tema, conhecer outros lugares, ter acesso a muitas informações sem precisar sair da escola. Dessa maneira, a escola, por meio dela, pode favorecer um novo encantamento do aluno na sua relação com a instituição de ensino. 0 pano de fundo desses estudos é o fato de que as tecnologias podem influenciar a maneira de aprender e compreender o mundo. Para Sodré (2009, p.29), as mudanças são profundas:

De fato, nesse nosso mundo hoje posto em rede técnica, modifica-se profundamente a experiência habitual do tempo, a da ordem temporal sucessiva, dando lugar à simultaneidade e à hibridização.

Um novo tipo de fluxo liga a estrutura em rede da moderna organização urbana às novas configurações da informação eletrônica. Nesse novo fluxo, começamos a ler e a ouvir de modo diferente.

O surgimento da web modificou a forma como as pessoas se relacionam:

Redes constituem a nova morfologia social de nossas sociedades e a difusão da lógica de redes modifica de forma substancial a operação e os resultados dos processos produtivos e de experiência, poder e cultura. [...] eu afirmaria que essa lógica de redes gera uma determinação social em nível mais alto que a dos interesses sociais específicos expressos por meio das redes: o poder dos fluxos é mais importante que os fluxos do poder. A presença na rede ou a ausência dela e a dinâmica de cada rede em relação às outras são fontes cruciais de dominação e transformação de nossa sociedade: uma sociedade que, portanto, podemos apropriadamente chamar de sociedade em rede, caracterizada pela primazia da morfologia social sobre a ação social. (Castells, 1999, p.565)

0 ponto interessante é que a internet e suas conexões tornaram possível 0 armazenamento de uma grande quantidade de informação sobre diferentes assuntos (Tüfekçi, 2014): big data, uma ferramenta para entender os campos da comunicação em diversos contextos da sociedade.

Benkler (2007, p.1) afirma que as "diversas mudanças tecnológicas, na organização econômica e nas práticas sociais de produção nesse ambiente, criaram novas oportunidades para produzirmos e trocarmos informações, conhecimento e cultura".

De certa forma, a maneira como informação, conhecimento e cultura são produzidas e distribuídas afeta criticamente a percepção das pessoas. "Por mais de 150 anos, democracias modernas complexas têm dependido em grande medida de uma economia industrial da informação para estas funções básicas" (Benkler, 2007, p.1). Mas, impulsionadas pelas TICs, percebem-se nas últimas duas décadas mudanças sociais, econômicas e culturais "que tornam possível uma transformação radical na forma como construímos o ambiente informacional que ocupamos como indivíduos autônomos, cidadãos e membros de grupos culturais e sociais" (Benkler, 2007, p.1). Essas mudanças favorecem ações colaborativas de produção de conteúdo não proprietárias que estão à margem do sistema de mercado de produção e distribuição de informação. Tais práticas têm apresentado sucesso em 
diversas áreas da economia, saindo da questão da produção da informação e passando pela produção de software, construção de bibliotecas colaborativas, participações em ações governamentais com foco em uma melhor governança etc.

Essa nova liberdade traz grandes promessas práticas: como uma forma de liberdade individual; como uma plataforma para melhor participação democrática; como um meio de fomentar uma cultura mais crítica e autorreflexiva; e, numa economia global cada vez mais dependente da informação, um mecanismo para obter melhorias no desenvolvimento humano em todo lugar. (Benkler, 2007, p.1)

Essa grande quantidade de dados gerados espontaneamente a cada ano tem sido alvo de empresas e governos interessados em entender o comportamento das pessoas. Tufekci (2014) cita que, além da engenharia social, existem outros métodos de análises que podem ser realizadas não só pelo viés da sociologia, mas também pelos dados. A combinação de análise de data com práticas computacionais possibilita ao pesquisador entrar em outro patamar de pesquisa no campo da comunicação, política e esporte, por exemplo.

Na educação já existem estudos sobre analytics learning ${ }^{1}$, ferramenta que coleta e mensura dados dos alunos em ambiente virtual de aprendizagem (AVA). Esses dados apontam se há ajustes a serem realizados na plataforma para garantir um melhor aprendizado. A coleta também auxilia na diminuição da evasão escolar, mapeando os estudantes que apresentam algum tipo de dificuldade dentro do AVA.

O fato é que, cada vez mais, o pesquisador adquire conhecimento técnico de determinadas ferramentas para analisar as informações disponíveis na rede. Esse pesquisador será reconhecido pelo seu toolkit ${ }^{2}$, e seu diferencial serão as ferramentas que utiliza. Ou seja, ele é reconhecido por suas práticas e pelo como se apropria das ferramentas disponíveis para a pesquisa.

Dessa maneira, é possível perceber que as mudanças produzidas nas últimas décadas afetaram diversas esferas da sociedade: a maneira como ensinamos e aprendemos, o relacionamento entre governo e sociedade, o perfil dos profissionais e a maneira como produzimos riqueza. A quantidade de informação disponível na internet, a mobilidade, o baixo custo da microtecnologia, a expansão da conexão e tantos outros fatores acabaram influenciando a maneira como nos relacionamos.

0 professor Milton Santos (1997, p.23) faz uma análise sobre os cinco períodos no desenvolvimento dos sistemas

período do comércio em grande escala (a partir dos fins do século XV até mais ou menos 1620); 2) 0 período manufatureiro (1620 - 1750); 3) 0 período da revolução industrial (1750 - 1870); 4) 0 período industrial (1870 - 1945); 5) 0 período tecnológico".

Ele conclui que o atual período tecnológico apresentou a evolução científica mais rápida e com grandes transformações econômicas e sociais. Trata-se do quinto período, que surge após a Segunda Guerra Mundial, tendo características completamente diferentes dos outros períodos apresentados. Para Santos (1997), esses períodos apresentam-se como sucessões de sistemas técnicos. Dessa maneira, percebe-se que cada período substitui o anterior com novos sistemas técnicos à medida que vão se modernizando e, consequentemente, alimentando o sistema capitalista.

A característica desse período é que as inovações tecnológicas se apresentam, além de juntas e associadas com outras áreas de conhecimento, "também para serem propagadas em conjunto. Isto é peculiar à natureza do sistema, em oposição ao que sucedia anteriormente, quando a propagação de diferentes variáveis não era necessariamente acelerada" (Santos, 1997, p.27).

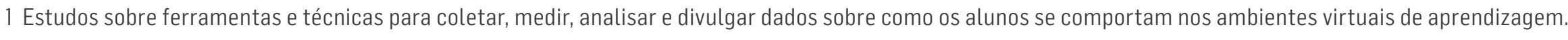

2 Conjunto de softwares que auxiliam o/a pesquisador (a). 
A questão do encurtamento do tempo e espaço, ligações intercontinentais via satélite, aviões, estradas, TICs, tudo isso tem um impacto na relação entre as pessoas, na maneira como aprendem, consomem e se relacionam. Essa rapidez na comunicação traz novas possibilidades e mudanças também no jeito de ser e ver o mundo.

Esta instantaneidade e universalidade na propagação de certas modernizações desmantela a organização do espaço anterior. Constitui, sobretudo, um fator de dispersão que se opõe de uma forma muito clara aos fatores de concentração conhecidos nos períodos anteriores. (Santos, 1997, p.29)

Porém a comunicação apresentada em alguns aplicativos e plataformas, muitas vezes de forma unilateral e de caráter hipnótico, pode ocasionar equívocos na percepção do mundo. Se anteriormente o homem estava muito mais conectado com a natureza, tirando somente dela seu sustento e aquilo de que precisava em determinado momento, agora a humanidade torna-se escrava de uma natureza abstrata, em que a ferramenta que era utilizada para servir o homem ${ }^{3} 0$ escraviza, uma vez que ele se tornou refém de técnicas que atendem a interesses de grandes corporações capitalistas, além de aumentarem seu distanciando e suas percepções sobre a natureza.

Na realidade, toda técnica éhistória embutida. Através dos objetos, a técnica éhistória no momento da sua criação e no de sua instalação e revela o encontro, em cada lugar, das condições históricas (econômicas, socioculturais, políticas, geográficas), que permitiram a chegada desses objetos e presidiram à sua operação. A técnica é tempo congelado e revela uma história. (Santos, 2006, p.40)

Empresas apresentam novas técnicas como revolucionárias ou como soluções para questões como a mobilidade urbana, geração de renda ou até mesmo no relacionamento entre diferentes atores, porém, em muitos casos, são meramente perfumarias tecnológicas interessadas em arrebanhar milhões de pessoas, tornando-se o novo Facebook ou Google, uma vez que organiza as informações dos usuários em big data e oferecem essas informações para parceiros e anunciantes sem sua anuências.

Santos (1997) afirma que as técnicas são neutras e os atores que as utilizam dão significado a elas. Porém percebe-se que emergem nesse quinto período técnico sentidos enviesados que atendem a interesses de atores hegemônicos. Esse cenário não está restrito somente ao Google ou Facebook, mas também se estende às startupse empresas que surgiram na chamada economia colaborativa, ganhando cada vez mais espaço na internet.

Os espaços assim requalificados atendem sobretudo aos interesses dos atores hegemônicos da economia, da cultura e da política e são incorporados plenamente às novas correntes mundiais. 0 meio técnico-científico informacional é a cara geográfica da globalização. (Santos, 1997, p.191)

Por exemplo, vejam-se as polêmicas que envolveram a Uber, como carga horária de trabalho excessiva por parte dos motoristas que aderem à plataforma e prestam serviço por meio dela, ausência de direitos básicos para esses trabalhadores, que dependem unicamente do rendimento gerado pela plataforma sem convênio médico, auxílio-doença, férias, hora-extra e outros direitos garantidos pela lei trabalhista brasileira. Esses pontos precisam de adequação, já que apresentam sinais de desgaste desse modelo de negócio.

Ainda sobre a afirmação de que os objetos são neutros (Santos, 1997b), o autor também diz que, quando introduzidos na sociedade, eles ganham relevância social. Um exemplo disso é a energia elétrica: antes de sua difusão, as pessoas aproveitavam a luz do sol para trabalhar e ter vida social, no final do dia elas se reuniam para conversar, até mesmo com fogueira e lampião, assim, de modo geral, dormiam e acordavam cedo para aproveitar a luz solar. Com o surgimento da energia elétrica houve

3 Entenda-se homem e mulher. 
uma mudança nas relações sociais. Tornou-se possível dormir mais tarde, já que havia energia elétrica para iluminar. Surgiram também os aparelhos eletrônicos, como rádio e, posteriormente, a televisão.

A tecnologia constitui não apenas uma esfera da realidade, mas uma ordem da realidade, possuidora de sua própria racionalidade [...]. As inovações técnicas se encontram com a história portando suas próprias regras, às quais as demais escolhas devem curvar-se. (SANTOS, 1997, p.238)

Há de considerar o impacto que as TIC's tiveram em diversos setores da sociedade. Na comunicação entre pessoas, a questão do espaço e tempo acabou sendo a minimizada em decorrência da facilidade de interconexão que os computadores e os dispositivos móveis oferecem entre os atores que têm acesso a esse tipo de tecnologia. Também é possível citar o impacto nas transações financeiras nos modelos de negócio, transporte, venda e compra de produtos; e na mecanização das empresas que têm substituído trabalhadores por máquinas. Tudo isso ocorre em função do barateamento dos dispositivos computacionais e do surgimento da internet.

"A nova onda de tecnologia é formada por três grandes forças: computadores e celulares baratos, Internet de baixo custo e fonte aberta. A tecnologia permite que os indivíduos se expressem e colaborem entre si" (Kotler, 2012, p.c7). Porém, "somente a História nos instrui sobre o significado das coisas. Mas é preciso sempre reconstruí-la para incorporar novas realidades e novas ideias ou, em outras palavras, para levarmos em conta o Tempo que passa e tudo muda" (Santos, 1992, p.7).

Porém, a partir do momento que as técnicas começaram a ganhar relevância na sociedade, ela ocupou espaço na vida cotidiana de homens e mulheres, algo que ganhou maior dimensão com a Revolução Industrial, visto que setores da sociedade começam a se apropriar das técnicas para satisfazer os interesses lucrativos de grandes corporações que produzem essas técnicas.

\section{CONSIDERAÇÕES FINAIS}

Hoje, qualquer pessoa que tenha um dispositivo eletrônico e conexão pode pesquisar em um rico banco de dados chamado internet, que fornece informações e pesquisas do mundo inteiro. Esse fluxo comunicacional proporcionado pela internet possibilitou que pessoas pudessem auxiliar com a sua capacidade excedente em pesquisas e desenvolvimento de produtos e serviços. Também permitiu que fossem criadas plataformas para auxiliar na ciência, jornalismo, financiamento, saúde, inovação e tantas outras possibilidades.

Do ponto de vista da informação disponível nas redes e da viabilidade de criar inovações a partir desse conhecimento disponível, quanto maior a quantidade de informação sobre determinado assunto, maior a possibilidade de o empreendedor viabilizar uma ideia. Outro ponto nesta discussão é que também há a tendência de grandes empresas buscarem parcerias com pequenos empreendedores e instituições de ensino para demandas reprimidas na pesquisa e desenvolvimento de produtos e serviços.

Dentro desse cenário de novas perspectivas tecnológicas, também é importante fazer uma reflexão crítica sobre o impacto dessas tecnologias no mercado de trabalho, na privacidade dos dados e na livre circulação de ideias. Com relação ao mercado de trabalho, há uma perspectiva extremamente sombria de diminuição de número de vagas tradicionais de emprego nos próximos anos em função do desenvolvimento tecnológico e da substituição da força de trabalho por máquinas. Esse impacto já vem ocorrendo e se fortaleceu com o avanço de ferramentas para inteligência artificial construídas ao longo dos últimos anos e alimentadas a partir da grande quantidade de dados produzidos e disponibilizados na internet. Um movimento importante seria as universidades entenderem essas novas demandas no mercado de trabalho e capacitarem novos profissionais não só tecnicamente, como também proporcionando uma reflexão crítica sobre esse novo período tecnológico. Se a mão de obra vem sendo substituída pela tecnologia e mecanização dos processos, a grande quantidade de dados tem gerado um ataque 
constante à privacidade dos indivíduos. A cada ação promovida, conscientemente ou não, produzimos e divulgamos nossos dados sem saber a dimensão de quem e para que essas informações são utilizadas. Apesar da grande euforia, já que essas informações podem auxiliar na segmentação do mercado e na promoção de bens e serviços, é importante ter atenção, pois cada vez mais saímos de uma sociedade em rede que permite que todos os indivíduos possam se manifestar livremente para entrar em uma sociedade do controle na qual cada clique ou ação pode ser compartilhada com outras pessoas.

\section{REFERÊNCIAS}

BENKLER, Yochai. A riqueza das redes. Cambridge, MA: Harvard University Press, 2007. Disponível em: https://bit.ly/2Adz4IE. Acesso em: 1 out. 2011.

CASTELLS, Manuel. Sociedade em rede. 6. ed. São Paulo: Paz e Terra, 1999.

CIEB. Inovação aberta em educação. São Paulo: Cieb, 2016. Disponível em: https://bit.ly/2lToRds. Acesso em: 16 set 2019.

KOTLER, Philip. Marketing 3.0: as forças que estão definindo o novo marketing centrado no ser humano. Rio de Janeiro: Elsevier, 2012.

PRENSKY, Marc. Nativose inmigrantes digitales. Madrid:SEK, 2010. Disponível em: https://bit.ly/2w6wfW6. Acesso em: 17 mar. 2018.

SANTOS, Milton. 1992: a redescoberta da Natureza. Estudos Avançados, São Paulo, v.6, n.14, p.95-106, 1992. Disponível em: https://bit.ly/2mddtcv. Acesso em: 17 mar. 2018.

SANTOS, Milton. A aceleração contemporânea: tempo-mundo e espaço-mundo. In: SANTOS, Milton. Técnica, espaço, tempo: globalização e meio técnico-científico informacional. São Paulo: Hucitec, 1998. p.29-39.

SANTOS, Milton. A natureza do espaço: técnica e tempo, razão e emoção. 4. ed. São Paulo: Edusp, 2006.

SANTOS, Milton. Espaço e método. São Paulo: Nobel, 1997.

SANTOS, Milton. Técnica, espaço, tempo: globalização e meio técnico-científico informacional. São Paulo: Hucitec, 1985.

SICHEL, Berta. Os elos subterrâneos da modernidade. Revista USP, São Paulo, n.2, p.145-148, 1989.

SODRÉ, Muniz. A narração do fato: notas para uma teoria do acontecimento. Petrópolis: Vozes, 2009.

THOMPSON, John B. A mídia e a modernidade: uma teoria social da mídia. 10. ed. Petrópolis: Vozes, 2008.

TÜFEKÇI, Zeynep. Engineering the public: big data, surveillance and computational politics. First Monday, Chicago, v.19, n7, 2014. 